\title{
A Calcium-Activated Nonselective Cation Conductance Underlies the Plateau Potential in Rat Substantia Nigra GABAergic Neurons
}

\author{
Christian R. Lee and James M. Tepper \\ Center for Molecular and Behavioral Neuroscience, Rutgers, The State University of New Jersey, Newark, New Jersey 07102
}

\begin{abstract}
Plateau potentials can be elicited in nigral GABAergic neurons by injection of $500 \mathrm{~ms}$ depolarizing current pulses from hyperpolarized holding potentials in whole-cell recordings in vitro. In approximately one-third of these neurons, plateau potentials were observed under control conditions and could be elicited in the remaining neurons after blocking potassium conductances. Application of the L-type calcium channel agonist Bay K 8644 or activation of NMDA receptors enhanced plateau potentials observed under control conditions and caused a plateau to be elicited in neurons not exhibiting it previously. The plateau potential was abolished in calcium-free buffer, as well as by nickel or cadmium. The L-type calcium channel blockers nimodipine and nifedipine abolished the plateau potential observed under control conditions but did not affect plateaus unmasked by tetraethylammonium. Plateau potentials observed under control conditions as well as those observed in the presence of Bay K 8644, NMDA, or tetraethylammonium were abolished in low-sodium buffer and by the calcium-activated nonselective cation conductance blocker flufenamic acid. These data suggest that nigral plateau potentials are mediated by a calcium-activated nonselective cation conductance $\left(I_{\mathrm{CAN}}\right)$ that is activated by calcium entry predominantly through L-type calcium channels. In many nigral neurons, $I_{\mathrm{CAN}}$ is masked by tetraethylammonium-sensitive potassium conductances, but plateaus can be evoked after increasing calcium conductances. The $I_{\mathrm{CAN}}$-mediated plateau potential in nigral GABAergic neurons likely affects the way these neurons integrate input and may represent a mechanism contributing to the rhythmic firing of these neurons seen in pathological conditions such as Parkinson's disease.
\end{abstract}

Key words: Parkinson's; $I_{\mathrm{CAN}}$; synaptic integration; synaptic communication; L-type; sodium; afterdepolarization; basal ganglia; burst; NMDA; tremor

\section{Introduction}

GABAergic neurons in the substantia nigra pars reticulata along with the entopeduncular nucleus and internal segment of the globus pallidus make up the major output of the basal ganglia and function to tonically inhibit and phasically disinhibit target neurons in the thalamus and the superior colliculus, thereby allowing movement (Albin et al., 1989; Chevalier and Deniau, 1990; DeLong, 1990). Nigral GABAergic neurons are spontaneously active both in vivo (Wilson et al., 1977; Deniau et al., 1978; Guyenet and Aghajanian, 1978; Celada et al., 1999; Windels and Kiyatkin, 2004) and in vitro (Nakanishi et al., 1987b; Lacey et al., 1989; Yung et al., 1991; Rick and Lacey, 1994; Richards et al., 1997; Atherton and Bevan, 2005), and the brief changes in firing rate that are responsible for movement are caused by afferent input (Lestienne and Caillier, 1986; Schultz, 1986; Chevalier and Deniau, 1990; Windels and Kiyatkin, 2006). Nigral GABAergic neurons receive inhibitory input primarily from the striatum (Bevan

\footnotetext{
Received Dec. 13, 2006; accepted May 4, 2007.

This work was supported by National Institute of Neurological Disorders and Stroke Grant NS34865. We thank Fulva Shah for excellent technical assistance and Prof. Denis Paré for helpful comments on this manuscript.

Correspondence should be addressed to James M. Tepper, Center for Molecular and Behavioral Neuroscience, Rutgers, The State University of New Jersey, 197 University Avenue, Newark, NJ 07102. E-mail: tepper@axon.rutgers.edu.

DOI:10.1523/JNEUROSCI.1678-07.2007

Copyright $\odot 2007$ Society for Neuroscience $\quad$ 0270-6474/07/276531-11\$15.00/0
}

et al., 1994), globus pallidus (Smith and Bolam, 1991), and other nigral GABAergic neurons (Deniau et al., 1982; Nitsch and Riesenberg, 1988; Hajos and Greenfield, 1994; Rick and Lacey, 1994; Gulácsi et al., 2003), whereas the majority of the excitatory afferents originate from the subthalamic nucleus (Robledo and Feger, 1990; Bevan et al., 1994). The final output of nigral GABAergic neurons in vivo results from an interaction between the afferent inputs and intrinsic membrane conductances.

In vitro recordings have described the presence of a depolarizing plateau potential in subsets of both nigral and entopeduncular GABAergic neurons in response to depolarizing current pulses or stimulation of the subthalamic nucleus (Matsuda et al., 1987; Nakanishi et al., 1987b, 1990, 1991). The conductances underlying the plateau potential could contribute to increased excitability in nigral GABAergic neurons and perhaps to changes in their firing patterns. Many of the behavioral pathologies of Parkinson's disease, and associated animal models, can be attributed to a shift away from tonic, regular firing in nigral GABAergic neurons to an irregular and bursty firing pattern that is likely caused, at least in part, by an increase in excitatory input from the subthalamic nucleus (Albin et al., 1989; DeLong, 1990; Bergman et al., 1994, 1998; Wichmann et al., 1994; Murer et al., 1997; Hurtado et al., 1999; Degos et al., 2005).

Despite the possible importance of the plateau potential to normal and pathological activity in pars reticulata, the mecha- 
nisms underlying this plateau have not been described. Here, we used in vitro visualized whole-cell current-clamp recordings to investigate the cellular mechanisms underlying plateau potential generation in rat nigral GABAergic neurons. We show that the plateau is caused by a calcium-activated nonselective cation conductance, which is activated by calcium entry through both voltage- and transmitter-dependent calcium conductances.

Portions of these data have been presented previously in abstract form (Lee and Tepper, 2005), and the baseline physiological and anatomical properties reported here include measurements from some neurons used previously (Lee and Tepper, 2007).

\section{Materials and Methods}

Whole-cell recordings. In vitro visualized whole-cell current-clamp recordings were performed on substantia nigra pars reticulata GABAergic neurons in $300 \mu \mathrm{m}$ coronal slices from 21- to 28-d-old male Sprague Dawley rats. All procedures were performed with the approval of the Rutgers University Institutional Animal Care and Use Committee and in accordance with the National Institutes of Health Guide for the Care and Use of Laboratory Animals. Animals were deeply anesthetized with 150 $\mathrm{mg} / \mathrm{kg}$ ketamine and $30 \mathrm{mg} / \mathrm{kg}$ xylazine intraperitoneally and transcardially perfused with chilled, modified Ringer's solution containing (in $\mathrm{mM}$ ) 225 sucrose, $2.5 \mathrm{KCl}, 0.5 \mathrm{CaCl}_{2}, 7 \mathrm{MgCl}_{2}, 28 \mathrm{NaHCO}_{3}, 1.25 \mathrm{NaH}_{2} \mathrm{PO}_{4}, 7$ glucose, 1 ascorbate, and 3 pyruvate, which was bubbled with $95 \% \mathrm{O}_{2}$ and $5 \% \mathrm{CO}_{2}$ until the blood had been replaced with this solution. The brain was then quickly removed and trimmed to a block containing the midbrain. Slices were cut in the same medium using a Vibroslice (model NVSL; World Precision Instruments, Sarasota, FL) and immediately transferred to warmed $\left(34^{\circ} \mathrm{C}\right)$ Ringer's solution composed of (in mM) $125 \mathrm{NaCl}, 2.5 \mathrm{KCl}, 1.25 \mathrm{NaH}_{2} \mathrm{PO}_{4}, 25 \mathrm{NaHCO}_{3}, 1 \mathrm{MgCl}_{2}, 2 \mathrm{CaCl}_{2}, 25$ glucose, 1 ascorbate, 3 pyruvate, and 0.4 myo-inositol, continuously bubbled with $95 \% \mathrm{O}_{2}$ and $5 \% \mathrm{CO}_{2}$ for $1 \mathrm{~h}$ before recording and then maintained at room temperature until use. Recordings were made in the same medium, which was heated to $34^{\circ} \mathrm{C}$ and perfused through the slice chamber at $\sim 5 \mathrm{ml} / \mathrm{min}$. Neurons were visualized at $40 \times$ with a waterimmersion objective on an Olympus (Tokyo, Japan) BX50WI fixed-stage microscope with infrared differential interference contrast microscopy and an MTI CCD-300 CCD camera (Dage-MTI, Michigan City, IN).

Pipettes were constructed from $1.5 \mathrm{~mm}$ outer diameter borosilicate capillary tubing (World Precision Instruments) using a PP-83 vertical pipette puller (Narishige International USA, East Meadow, NY). The pipette solution contained (in $\mathrm{mM}$ ) 129 potassium gluconate, $11 \mathrm{KCl}, 10$ HEPES, $2 \mathrm{MgCl}_{2}$, 10 EGTA, $3 \mathrm{Na}_{2}$-ATP, and $0.3 \mathrm{Na}_{3}$-GTP, into which $0.3 \%$ biocytin (Sigma-Aldrich, St. Louis, MO) was dissolved by sonication. Pipettes possessed resistances of 4-6 M $\Omega$. In some experiments, potassium gluconate was replaced by an equimolar concentration of potassium methyl sulfate.

Recordings were amplified with a Neurodata IR-283 amplifier and sampled at $40 \mathrm{kHz}$ using a Micro1401 mk II digitizer (Cambridge Electronic Design, Cambridge, UK) and a personal computer running Signal version 3.05 (Cambridge Electronic Design). Data were analyzed using the same program.

The substantia nigra pars reticulata contains both GABAergic and dopaminergic neurons. The GABAergic neurons differ from the dopaminergic neurons in terms of their higher firing rate, shorter duration action potential, short latency and small amplitude afterhyperpolarization, and a much less pronounced voltage sag in response to hyperpolarizing current pulses (see Results and Table 1) (Matsuda et al., 1987; Nakanishi et al., 1987b; Grace and Onn, 1989; Yung et al., 1991; Lacey et al., 1989; Richards et al., 1997; Iribe et al., 1999; Gulácsi et al., 2003). These criteria were the primary factors in differentiating nigral GABAergic neurons from dopaminergic neurons, and the data presented here come from neurons that were inferred to be GABAergic based on these characteristics.

In cases in which cells were later assessed using immunocytochemistry, slices were immediately placed into chilled $4 \%$ paraformaldehyde in $0.1 \mathrm{M}$ phosphate buffer (PB), $\mathrm{pH} 7.4$, after recording where they were stored overnight at $4^{\circ} \mathrm{C}$. In these cases, all efforts were made to reduce dilution of intracellular antigens with the pipette solution by minimizing the recording time ( $<5 \mathrm{~min})$.

Drug preparation and delivery. Drugs were dissolved in either recording buffer or dimethyl sulfoxide where appropriate and bath applied. Final concentrations of dimethyl sulfoxide were between 0.05 and $0.1 \%$. Tetrodotoxin citrate (TTX) and 4-( $N$-ethyl- $N$-phenylamino)-1,2dimethyl-6-(methylamino)pyridinum chloride (ZD 7288) were purchased from Tocris Bioscience (Ellisville, MO). Bay K 8644, cadmium chloride, choline bicarbonate, choline chloride, flufenamic acid, nickel chloride, nifedipine, nimodipine, NMDA, and tetraethylammonium chloride (TEA) were purchased from Sigma-Aldrich. Calcium-free buffer was made by removing calcium chloride from the recording solution and replacing it with an equimolar concentration of cobalt chloride (Fisher BioReagents, Fair Lawn, NJ). In these cases, sodium phosphate was also omitted. Low-sodium buffer was made by substituting equimolar concentrations of choline chloride and choline bicarbonate for sodium chloride and sodium bicarbonate, respectively.

Immunocytochemistry. Immunocytochemistry was performed as described previously (Lee and Tepper, 2007). Briefly, sections were incubated in a solution containing 1:1500 rabbit anti-calretinin polyclonal antibody (\#AB5054; Millipore, Billerica, MA) and 1:1500 mouse antiparvalbumin monoclonal antibody (\#P 3088; Sigma-Aldrich) along with $10 \%$ normal goat serum, $2 \%$ bovine serum albumin, and $0.5 \%$ Triton

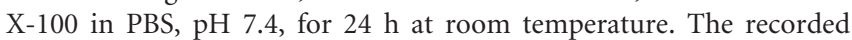
neuron was revealed with 7-amino-4-methylcoumarin-3-acetic acid conjugated streptavidin, calretinin with cyanine 3 , and parvalbumin with Oregon Green. After immunocytochemical identification, sections were incubated with avidin-biotin peroxidase and reacted with $3,3^{\prime}$ diaminobenzidine $(0.025 \%)$ and $\mathrm{H}_{2} \mathrm{O}_{2}(0.0008 \%)$ in $\mathrm{PB}$ with nickel intensification. The sections were then embedded between glass slides and coverslips. Somatic measurements were obtained from neurons photographed at $40 \times$ to $100 \times$ using a Leica (Nussloch, Germany) DMRE microscope and a Hamamatsu (Bridgewater, NJ) Orca-ER digital camera and Openlab version 4.0.2 (Improvision, Boston, MA). The shape factor is equal to $4 \mathrm{~A} / \mathrm{P}^{2}$, where $\mathrm{A}$ is the area and $\mathrm{P}$ is the perimeter of the measured neuron. Neurons were drawn under a $60 \times$ oil-immersion objective using a Nikon (Tokyo, Japan) Optiphot microscope fitted with a drawing tube.

Data analysis. To measure the decay time of the plateau potential, plateaus were evoked by a $500 \mathrm{~ms}$ depolarizing pulse from neurons hyperpolarized to prevent spontaneous spiking by injection of constant current. The decay time was determined by calculating the time required for the membrane potential of the neurons to return to the baseline voltage recorded $10 \mathrm{~ms}$ before onset of the pulse. Only traces that were devoid of spiking after cessation of the depolarizing current pulse were used in these measurements. Traces with depolarizing current pulses of the same amplitude were chosen when comparing the decay time in different experimental conditions. If necessary, the prepulse membrane potential was maintained as close as possible to the potential measured under control conditions using different bias currents. Sag amplitudes were measured from the voltage difference between the most hyperpolarized voltage achieved during a $500 \mathrm{~ms}, 200$ pA hyperpolarizing current pulse delivered from rest and the voltage measured $500 \mu$ s before current offset. Action potential and other baseline physiological measurements were obtained as described previously (Lee and Tepper, 2007). Basic action potential parameters were measured from four consecutive spontaneous action potentials and averaged. The input resistance was assessed from single, small-amplitude hyperpolarizing current pulses delivered from rest, which were sufficient to halt spiking and calculated from the difference between the voltage $50 \mu$ s before current onset and the most hyperpolarized voltage obtained during the current pulse. The threshold was defined as the membrane potential at the time point reaching $15 \%$ of the maximum rising slope achieved during the action potential upstroke, and action potential amplitudes were calculated as the difference between the threshold and the peak of the action potential. The spontaneous action potential width was measured at half-amplitude between the action potential threshold and the peak of the action potential. The afterhyperpolarization amplitude and trough time were determined by cal- 
Table 1. Comparison of the electrophysiological characteristics of neurons exhibiting and not exhibiting a plateau potential when depolarized from a hyperpolarized holding potential

\begin{tabular}{|c|c|c|c|c|c|c|c|c|}
\hline Physiological type & $\begin{array}{l}\text { Input resistance } \\
(\mathrm{M} \Omega)\end{array}$ & AP threshold (mV) & $\begin{array}{l}\text { AP amplitude } \\
(\mathrm{mV})\end{array}$ & $\begin{array}{l}\text { AP width } \\
\text { (ms) }\end{array}$ & $\begin{array}{l}\text { Afterhyperpolarization } \\
\text { amplitude (mV) }\end{array}$ & $\begin{array}{l}\text { Afterhyperpolarization } \\
\text { latency (ms) }\end{array}$ & $\begin{array}{l}\text { Firing rate } \\
(\mathrm{Hz})\end{array}$ & $\begin{array}{l}\text { Sag amplitude } \\
(\mathrm{mV})\end{array}$ \\
\hline Plateau $(n=20)$ & $327.02 \pm 22.11$ & $-49.66 \pm 0.89$ & $66.92 \pm 1.36^{*}$ & $0.35 \pm 0.0 .2$ & $22.04 \pm 1.11$ & $1.29 \pm 0.07$ & $19.31 \pm 1.62$ & $7.04 \pm 0.75$ \\
\hline Nonplateau $(n=41)$ & $359.97 \pm 23.35$ & $-51.72 \pm 0.96$ & $72.07 \pm 1.07$ & $0.33 \pm 0.01$ & $22.05 \pm 0.83$ & $1.26 \pm 0.08$ & $16.86 \pm 0.99$ & $5.76 \pm 0.60$ \\
\hline Combined $(n=61)$ & $349.17 \pm 17.29$ & $-51.05 \pm 0.71$ & $70.38 \pm 0.90$ & $0.33 \pm 0.01$ & $22.05 \pm 0.66$ & $1.27 \pm 0.06$ & $17.66 \pm 0.86$ & $6.18 \pm 0.47$ \\
\hline
\end{tabular}

The electrophysiological characteristics were largely similar between the two populations with the exception that the action potential amplitude of neurons with a plateau potential was significantly smaller when compared with those without $\left({ }^{*} p<0.01\right)$. The combined averages are also shown. Input resistance was measured from a small, hyperpolarizing current pulse delivered from rest, which was sufficient to halt spiking. Action potential data were measured starting from the threshold, which was defined as the point reaching $15 \%$ of the maximum rising slope achieved during the action potential upstroke. The action potential width was measured at half-amplitude. Firing rate was measured from a 1 s sample of spontaneous activity. Data are presented as mean \pm SEM.

culating the difference between the threshold and the most negative voltage measured during the afterhyperpolarization. The spontaneous firing rate was calculated for each neuron from a $1 \mathrm{~s}$ sweep of spontaneous activity.

All data are presented as mean \pm SEM. Mean values were compared using paired or unpaired $t$ tests where appropriate, with the criterion for significance set to $p<0.05$. Statistics were computed using SAS version 8.02 (SAS Institute, Cary, NC).

Voltages reported have been corrected for the liquid junction potential, which was estimated to be $14.4 \mathrm{mV}$ using JPCalc (Barry, 1994).

\section{Results}

Measurements of the basal electrophysiological parameters from a sample of the recorded neurons are summarized in Table 1. All neurons exhibited regular spontaneous spiking at rest (Fig. $1 A, D$, Table 1 ) and a variable, although modest voltage sag in response to hyperpolarizing current pulses (mean, $6.21 \pm 0.41$ $\mathrm{mV}$; range, $0.43-18.02 \mathrm{mV} ; n=78$ ). The voltage sag in nigral dopaminergic neurons is caused by the presence of $I_{\mathrm{h}}$ and is abolished by ZD 7288 (Harris and Constanti, 1995; Neuhoff et al., 2002). Similarly, ZD $7288(30 \mu \mathrm{M})$ caused a significant reduction in sag amplitudes observed in nigral GABAergic neurons in response to hyperpolarizing current pulses $(6.32 \pm 0.83$ to $2.29 \pm$ $0.28 \mathrm{mV} ; t=-4.09 ; p<0.001 ; n=17)$, suggesting that the sag seen in these neurons is also caused by $I_{\mathrm{h}}$ (data not shown) (Atherton and Bevan, 2005).

\section{Plateau potentials are present in a subset of nigral GABAergic neurons after depolarization}

A subset of nigral GABAergic neurons responded to modest depolarizing current pulses from rest with a protracted increase in firing rate outlasting the depolarizing current pulse (Fig. 1B), whereas this effect was absent in others (Fig. $1 E$ ). When depolarized from a hyperpolarized holding potential with a $500 \mathrm{~ms}$ depolarizing pulse, neurons that exhibited an increase in spontaneous firing after the pulse also exhibited a depolarizing plateau potential that outlasted the current pulse (Fig. 1C). A plateau potential was observed in 269 of 867 neurons (31\%) under control conditions and was frequently of sufficient amplitude to support spiking (Fig. $2 \mathrm{~B}$ ). In contrast, neurons not exhibiting increased firing after the depolarizing pulse from rest lacked the plateau potential when hyperpolarized (Fig. $1 F$ ).

The plateau potential could be observed under control conditions regardless of whether the pipette solution was potassium gluconate based or potassium methyl sulfate based (supplemental Fig. 1, available at www.jneurosci.org as supplemental material).

These results, especially the prolonged increase in firing rate after depolarization from rest, suggest that the mechanism underlying the plateau potential operates at membrane potentials seen during the spontaneous activity of the neuron. However, the

\section{A}

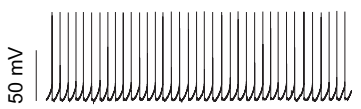

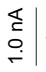

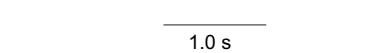

B
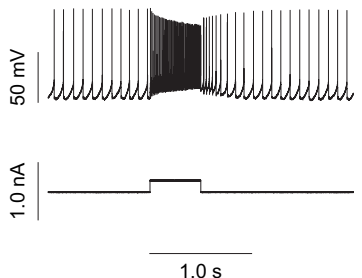

C

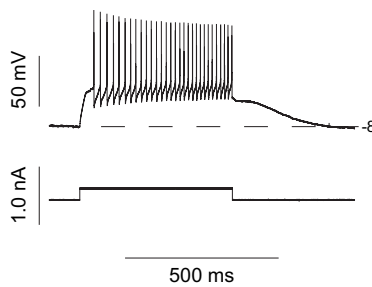

$\mathrm{F}$

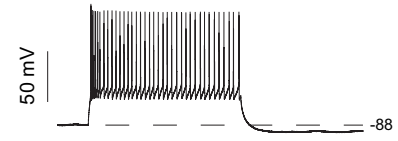

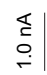
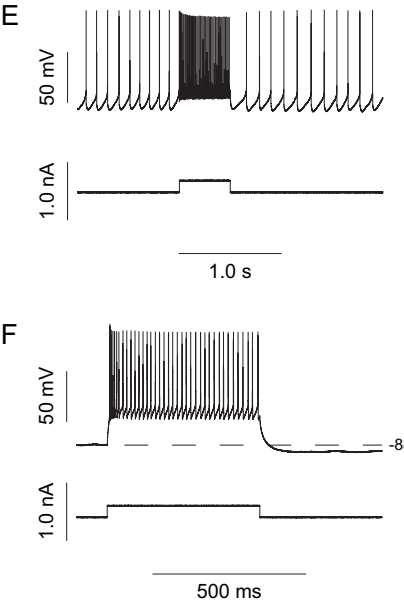

Figure 1. The plateau potential causes a prolonged increase in firing rate after depolarization from rest. $A$, A nigral GABAergic neuron exhibiting regular spontaneous activity at rest responds to a modest depolarizing current pulse delivered from rest with a prolonged increase in firing rate $(\boldsymbol{B})$. $\boldsymbol{C}$, The same neuron exhibits a plateau potential in response to a depolarizing current pulse when delivered from a hyperpolarized holding potential. $\boldsymbol{D}$, Another nigral GABAergic neuron also exhibits regular spontaneous activity at rest but does not respond to a current pulse with a prolonged increase in firing rate when depolarized from rest $(\boldsymbol{E})$. $\boldsymbol{F}$, This neuron did not exhibit a plateau potential in response to a depolarizing current pulse when hyperpolarized. Therefore, the conductance underlying the plateau potential can be activated within the normal membrane potential range of a spontaneously active neuron. In this and the following figures, the voltages indicated refer to the approximate hyperpolarized holding voltage of the neurons before onset of the current pulse.

basal physiological properties did not differ between neurons exhibiting the plateau, and those not exhibiting the plateau, except for the action potential amplitude, which appeared to be significantly smaller in neurons exhibiting the plateau (Table 1). Therefore, the plateau potential is most likely to affect the physiology of the neuron when it is perturbed from its spontaneous activity, as would be the case in response to depolarizing synaptic input.

In some neurons, action potentials occurring during the depolarizing current pulse exhibited acceleration in their firing frequency, suggesting that the plateau may contribute to increased firing rates during the depolarizing current pulse (Figs. 1C, $2 \mathrm{~B}$ ). There was considerable variability in the expression of this firing 
A
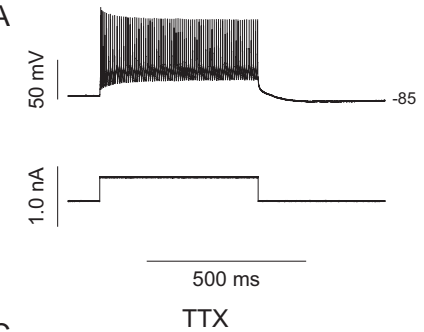

C

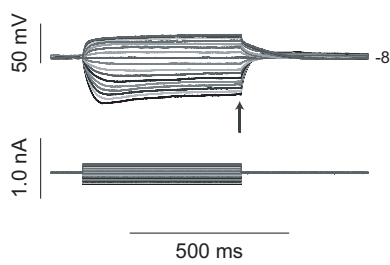

B
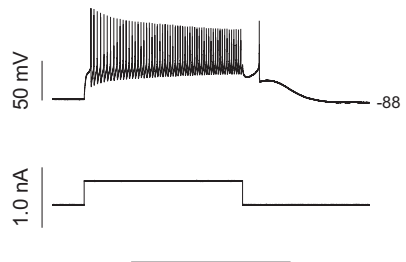

$500 \mathrm{~ms}$

D

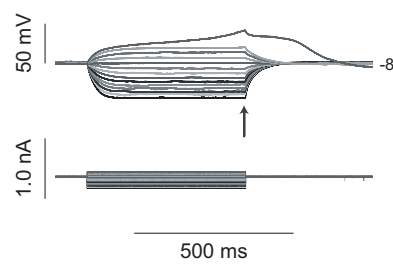

E

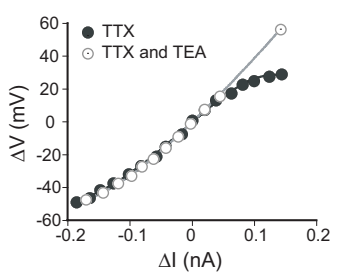

G

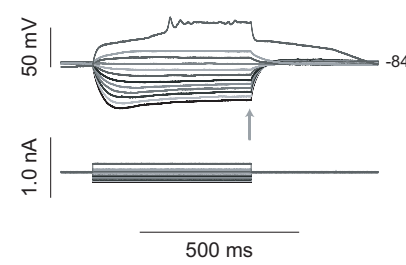

F

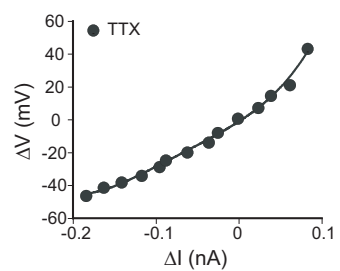

TEA

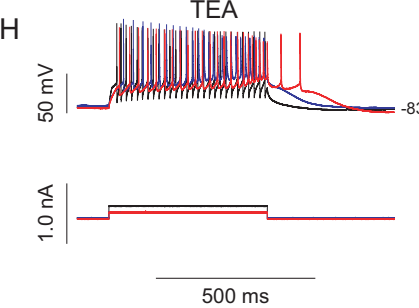

Figure 2. Plateau potentials in nigral GABAergic neurons can be observed after depolarizing pulses under control conditions or can be unmasked by TEA. $A$, When held hyperpolarized, the majority (69\%) of nigral GABAergic neurons responded to depolarizing current pulses with a depolarization that decayed rapidly after cessation of the depolarizing current. $\boldsymbol{B}$, However, $31 \%$ of the neurons were observed to exhibit a depolarizing plateau potential that outlasted the current injection. $C, D$, When action potentials were blocked in each of these neurons by application of TTX (2 $\mu \mathrm{M})$, neurons that did not exhibit the plateau potential showed strong outward rectification in their current-voltage relationships, as shown for this neuron in $\boldsymbol{E}$ (closed circles), whereas neurons exhibiting the plateau did not, as seen in $\boldsymbol{F}$. Blocking potassium channels in non-plateau-generating neurons with TEA ( $30 \mathrm{~mm})$ in the presence of TTX (2 $\mu \mathrm{M})$ invariably resulted in the emergence of a plateau as shown for the same neuron $(\boldsymbol{G})$, and the elimination of outward rectification as seen in the current-voltage relationship in $\boldsymbol{E}$ (open circles). $\boldsymbol{H}$, Additionally, neurons that did not exhibit a plateau potential under control conditions (black trace) could be made to do so by blocking potassium channels with TEA alone ( $30 \mathrm{~mm}$; blue and red traces), as shown here in a third neuron. Thus, most if not all nigral GABAergic neurons are capable of generating a plateau potential, but under most conditions the plateau is masked by TEA-sensitive potassium conductances. Current-voltage relationships were measured at the point indicted by the arrows in $\mathbf{C}, \mathbf{D}$, and $\mathbf{G}$.

frequency acceleration (FFA), with some neurons exhibiting the plateau exhibiting little to no FFA (Fig. $3 A, C$ ) and other neurons not exhibiting the plateau that did show FFA.

\section{Anatomical properties and calcium- binding protein immunoreactivity of plateau and nonplateau neurons}

Like the physiological properties, the morphological properties of neurons exhibiting a plateau after depolarization were similar to those not exhibiting a plateau. The only significant difference found between neurons exhibiting a plateau after depolarization and those that did not was that the neurons exhibiting the plateau tended to have smaller areas. These results are summarized in Table 2.

Most nigral GABAergic neurons express immunoreactivity for either of the calcium-binding proteins parvalbumin or calretinin, with an exceedingly small proportion exhibiting immunoreactivity for both (Gonzalez-Hernandez and Rodriguez, 2000; Lee and Tepper, 2007). Of neurons exhibiting the plateau $(n=18)$, 11 expressed immunoreactivity for parvalbumin, 4 for calretinin, and 3 failed to express immunoreactivity for either calcium-binding protein. For those not exhibiting the plateau $(n=36), 14$ expressed immunoreactivity for parvalbumin, 12 for calretinin, and 10 failed to express immunoreactivity for either calcium-binding protein. Therefore, parvalbumin and calretinin do not show preferential distribution within neurons based on the presence or absence of a plateau $\left(X^{2}=2.39 ; p=0.30\right)$.
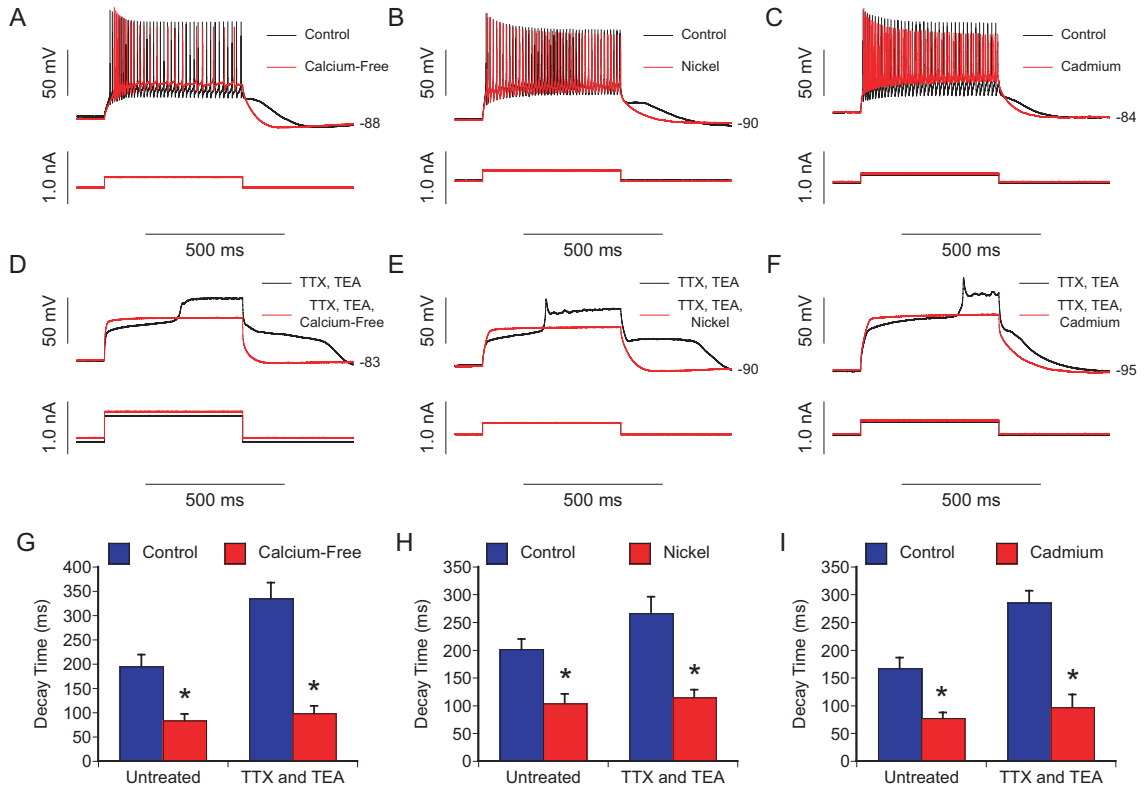

Figure 3. The plateau potential is dependent on calcium. $\boldsymbol{A}-\boldsymbol{C}$, The plateau potential elicited by a depolarizing current pulse under control conditions (black traces) was abolished by superfusion of calcium-free buffer $(\boldsymbol{A})$ or the calcium channel blockers nickel (500 $\mu \mathrm{m} ; \boldsymbol{B}$ ) or cadmium (400 $\mu \mathrm{m}$; , red traces). $\boldsymbol{D}-\boldsymbol{F}$, Similarly, the plateau potential unmasked by TEA (30 mm) in the presence of TTX ( $2 \mu \mathrm{m}$; black traces) was also abolished by calcium-free buffer $(\boldsymbol{D})$, nickel (1 mm; $\boldsymbol{E}$ ), or cadmium ( $400 \mu \mathrm{m} ; \boldsymbol{F}$, red traces). $\mathbf{G}-\mathbf{I}$, The bar graphs show that the mean plateau decay time after a depolarizing current pulse was significantly shortened by each of these. Thus, the plateau potential is dependent on calcium. ${ }^{*} p<0.01$.
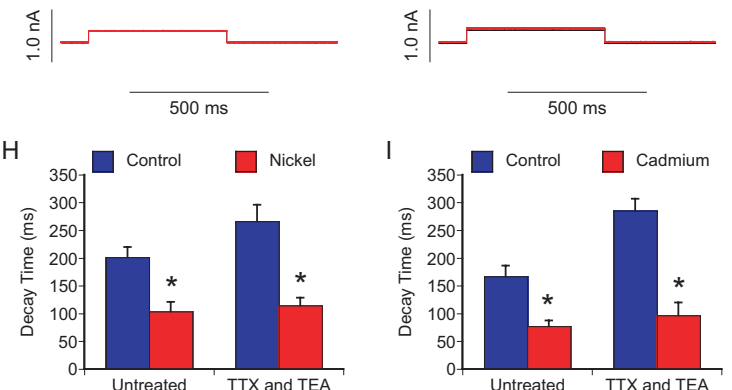
Table 2. Comparison of the morphometric characteristics of neurons exhibiting and not exhibiting a plateau potential

\begin{tabular}{llll}
\hline Physiological Type & Area $\left(\mu \mathrm{m}^{2}\right)$ & Perimeter $(\mu \mathrm{m})$ & Shape \\
\hline Plateau $(n=19)$ & $154.70 \pm 8.50^{*}$ & $53.57 \pm 1.56$ & $0.68 \pm 0.03$ \\
Nonplateau $(n=29)$ & $184.48 \pm 6.40$ & $56.51 \pm 1.13$ & $0.72 \pm 0.01$ \\
Combined $(n=48)$ & $172.69 \pm 5.50$ & $55.35 \pm 0.93$ & $0.71 \pm 0.01$
\end{tabular}

The morphometric characteristics were largely similar between the two populations of neurons with the exception that the area measured in neurons exhibiting a plateau was smaller than that observed in the other neurons $\left({ }^{*} p<\right.$ 0.01). The combined averages are also shown. Data are presented as mean \pm SEM.

previously in vivo and in vitro (Deniau et al., 1982; Mailly et al., 2001, 2003; Lee and Tepper, 2007).

\section{Ionic mechanisms underlying plateau potentials in nigral GABAergic neurons}

The plateau potential was not blocked by TTX in any neuron ( 2 $\mu \mathrm{M}$ ) (Fig. 2D). When the current-voltage relation was compared between neurons exhibiting the plateau under control conditions, and those from which the plateau was absent, the latter were found to exhibit strong outward rectification that was not present in neurons exhibiting a plateau (Fig. 2E,F). However, superfusion of TEA (10-30 mM) in addition to TTX abolished the outward rectification (Fig. $2 E, G$ ) and invariably revealed a latent plateau potential in neurons not exhibiting it under control conditions (Fig. $2 \mathrm{H}$ ). These results suggest that the plateau is resistant to block by TTX, and that most, if not all, nigral GABAergic neurons are capable of generating a plateau potential, but under most conditions, it is masked by TEA-sensitive potassium conductances.

\section{The role of calcium}

Replacement of $\mathrm{CaCl}_{2}$ with an equimolar concentration of $\mathrm{CoCl}_{2}$ in the bath led to a complete abolition of the plateau potential observed after depolarization under control conditions, as did the addition of nickel $(500 \mu \mathrm{M}$ to $1 \mathrm{mM})$ or cadmium $(400 \mu \mathrm{M})$ (Fig. $3 A-C$ ). This was evident as a decrease in the plateau decay time after the depolarizing current pulse after removal of calcium from the recording medium $(194.6 \pm 24.7$ to $83.4 \pm 13.6 \mathrm{~ms} ; t=$ $-8.80 ; p<0.01 ; n=4)$ or by the addition of nickel $(201.4 \pm 18.1$ to $103.5 \pm 17.2 \mathrm{~ms} ; t=-10.00, p<0.01, n=4$ ) or cadmium $(166.7 \pm 19.8$ to $77.1 \pm 10.1 \mathrm{~ms} ; t=-5.30 ; p<0.01 ; n=6)$. Similar results were obtained with the plateau unmasked by TEA in the presence of TTX (Fig. 3D-F). Under these conditions, the plateau decay time was also significantly reduced by removal of calcium $(334.5 \pm 32.7$ to $98.2 \pm 15.3 \mathrm{~ms} ; t=-6.96 ; p<0.01 ; n=$ $5)$ or the addition of nickel $(266.2 \pm 29.7$ to $114.5 \pm 13.8 \mathrm{~ms} ; t=$ $-4.70 ; p<0.01 ; n=9)$ or cadmium $(285.0 \pm 21.6$ to $96.8 \pm 23.0$ ms; $t=-11.53 ; p<0.0001 ; n=6$ ) (Fig. $3 G-I$ ). These results suggested that the plateau is dependent on calcium.

To determine the calcium channel subtype involved, the effects of the L-type calcium channel blockers nimodipine $(10 \mu \mathrm{M})$ and nifedipine (5-30 $\mu \mathrm{M})$ on the plateau were assessed (Fig. 4). The plateau observed under control conditions, or in the presence of TTX, was completely abolished by nimodipine $(286.3 \pm$ 23.4 to $137.9 \pm 16.8 \mathrm{~ms} ; t=-5.44 ; p<0.001 ; n=11)$, as well as by two concentrations of nifedipine $(30 \mu \mathrm{M} ; 231.7 \pm 32.7$ to $80.9 \pm 17.5 \mathrm{~ms} ; t=-5.97 ; p=0.001 ; n=7 ; 5 \mu \mathrm{M} ; 217.5 \pm 9.4$ to $116.7 \pm 15.1 \mathrm{~ms} ; t=-8.89 ; p<0.001 ; n=5)$. Identical results were obtained regardless of whether TTX was first used to block action potentials before application of nimodipine along with TTX (Fig. $4 B)(n=5)$. The plateau continued to be abolished by nimodipine even if the neurons were strongly depolarized, allowing the maximum voltage achieved during the depolarizing cur-
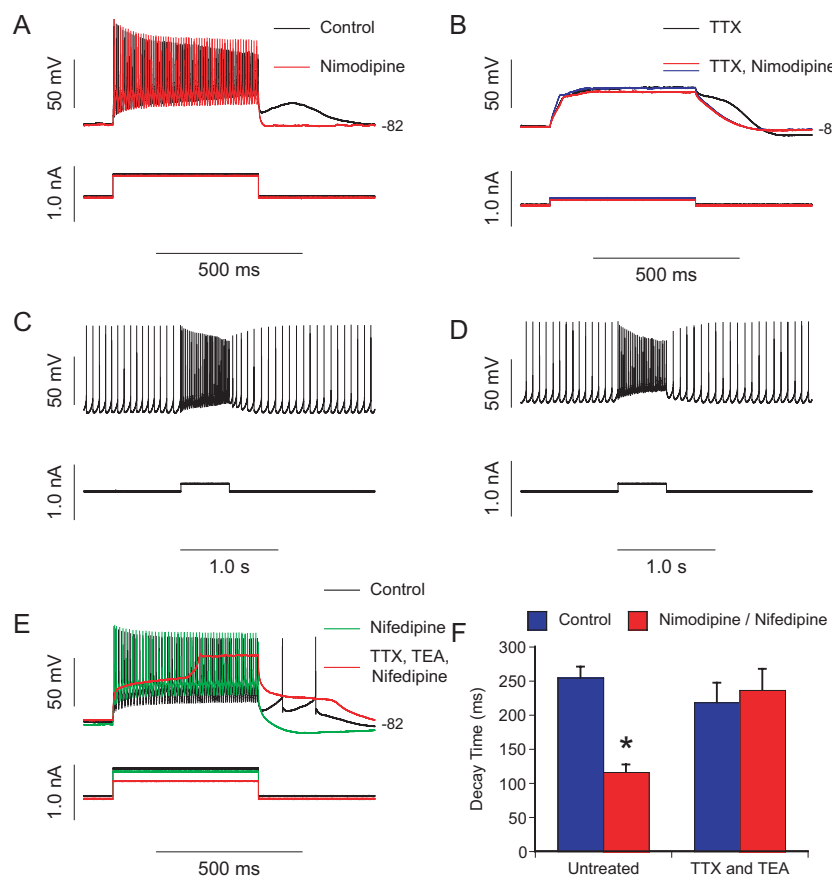

Figure 4. The plateau potential observed under control conditions is abolished by the specific L-type calcium channel blockers nimodipine and nifedipine. $A$, The plateau potential elicited from a depolarizing current pulse under control conditions (black trace) was abolished by nimodipine (10 $\mu \mathrm{m}$; red trace). $\boldsymbol{B}$, When spiking was blocked with TTX (black trace), the plateau persisted, but was blocked when nimodipine was added in addition to TTX (red trace). When the neuron was strongly depolarized to the voltage achieved with TTX alone, the plateau continued to be blocked (blue trace). $\boldsymbol{C}, \boldsymbol{D}$, The prolonged increase in firing rate observed after the depolarizing current pulse $(\boldsymbol{C})$ was abolished by nimodipine $(\boldsymbol{D})$. $\boldsymbol{E}$, The plateau potential under control conditions (black trace) was similarly abolished by nifedipine ( $30 \mu \mathrm{m}$; green trace), but restored by adding TEA ( $30 \mathrm{~mm}$ ) and TTX $(2 \mu \mathrm{m})$ in addition to nifedipine (red trace). An identical result was obtained with TEA, TTX, and nimodipine. The results for nimodipine and nifedipine were combined and are summarized in the bar graph in $\boldsymbol{F}$. Thus, L-type calcium channels can mediate the activation of the conductance underlying the plateau potential but are not responsible for producing it themselves. ${ }^{*} p<0.0001$.

rent pulse to reach that achieved during depolarization in the presence of TTX but without nimodipine (Fig. $4 B$, blue trace). Additionally, the prolonged increase in firing rate outlasting depolarizing current pulses delivered from rest was blocked by nimodipine (Fig. 4C,D). In contrast, neither nimodipine nor nifedipine was effective at blocking the plateau unmasked by TEA in the presence of TTX (218.5 \pm 28.6 to $236.5 \pm 30.9 \mathrm{~ms} ; t=1.18$; $p=0.28 ; n=8$ ) (Fig. $4 E$ ). These results suggest that although the plateau potential is dependent on an L-type calcium conductance control conditions, the calcium conductance does not underlie the plateau itself.

In addition to being attenuated when calcium conductances were blocked, the plateau was enhanced when calcium conductances were increased (Fig. 5). Both the L-type calcium channel agonist Bay K $8644(5 \mu \mathrm{M})$ and the NMDA receptor agonist NMDA $(20-30 \mu \mathrm{M})$ enhanced plateaus, which were observed under control conditions and elicited a plateau after depolarization in neurons not previously exhibiting it under control conditions or if action potentials were first blocked with TTX (Bay K 8644: $105.4 \pm 7.2$ to $279.5 \pm 13.6 \mathrm{~ms}, t=15.75, p<0.0001, n=$ 27; NMDA: $97.3 \pm 8.2$ to $228.7 \pm 18.6 \mathrm{~ms}, t=9.34, p<0.0001$, $n=20)$ (Fig. $7 B, D)$.

The role of sodium

The previous experiments established that the plateau is dependent on calcium conductances but implied that the conductance 


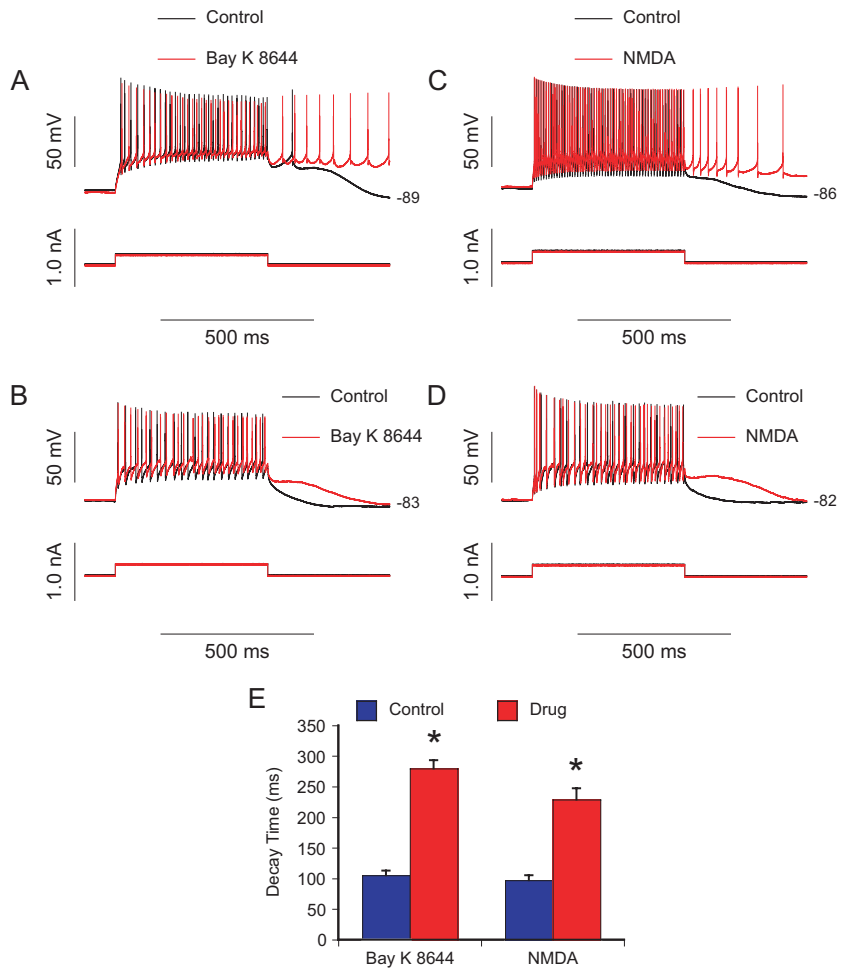

Figure 5. The plateau potential is enhanced by increasing calcium conductances. The L-type calcium channel agonist Bay K8644 (5 $\mu \mathrm{m}$ ) enhanced a plateau potential present under control conditions ( $\boldsymbol{A}$; black trace, control; red trace, Bay $\mathrm{K} 8644$ ) and elicited a plateau potential from a neuron not exhibiting it under control conditions ( $\boldsymbol{B}$; black trace, control; red trace, Bay K 8644). Similarly, superfusion of NMDA (20 $\mu \mathrm{M})$ enhanced a plateau potential elicited under control conditions ( $\boldsymbol{C}$; black trace, control; red trace, NMDA) and elicited a plateau potential from a neuron not exhibiting it under control conditions ( $\boldsymbol{D}$; black trace, control; red trace, NMDA). Similar results were obtained if action potentials were first blocked with TTX (see Fig. $7 B, D$ ). These results are summarized in $\boldsymbol{E}$. Thus, increasing calcium conductances enhances the plateau potential and increases the excitability of the neuron. ${ }^{*} p<0.0001$.

underlying the plateau does not use calcium as its main charge carrier. Rather, calcium appeared to be activating a conductance that uses another ion as its main charge carrier. The contribution of sodium to the plateau potential was assessed by replacing the majority of the extracellular sodium ions with an equimolar concentration of choline (see Materials and Methods). Because this also abolished action potential discharge, in some cases, TTX (2 $\mu \mathrm{M})$ was applied before switching to low-sodium buffer to minimize the differences between the two conditions. Elimination of most sodium ions from the extracellular solution completely abolished the plateau potential regardless of whether action potentials were first blocked by TTX $(262.6 \pm 18.0$ to $107.4 \pm 7.3$ $\mathrm{ms} ; t=-8.76 ; p<0.0001 ; n=13$ ) (Fig. $6 A, B$ ). The plateau potential continued to be abolished in low-sodium buffer with TTX when the neuron was strongly depolarized, allowing the voltage achieved during the depolarizing current pulse to reach that achieved during TTX in standard buffer, thus arguing against a threshold effect (Fig. 6C). Additionally, the plateau unmasked by TEA in the presence of TTX was also abolished under conditions of low sodium $(266.4 \pm 25.7$ to $108.8 \pm 14.9 \mathrm{~ms} ; t=$ $-7.32 ; p<0.0001 ; n=10$ ) (Fig. $6 D$ ). Thus, the plateau potential is caused by a TTX-resistant, calcium-activated conductance that uses sodium as its main charge carrier.

As shown previously, increasing calcium conductances through L-type calcium channels with Bay K 8644 as well as increasing NMDA conductances could elicit the plateau. This effect
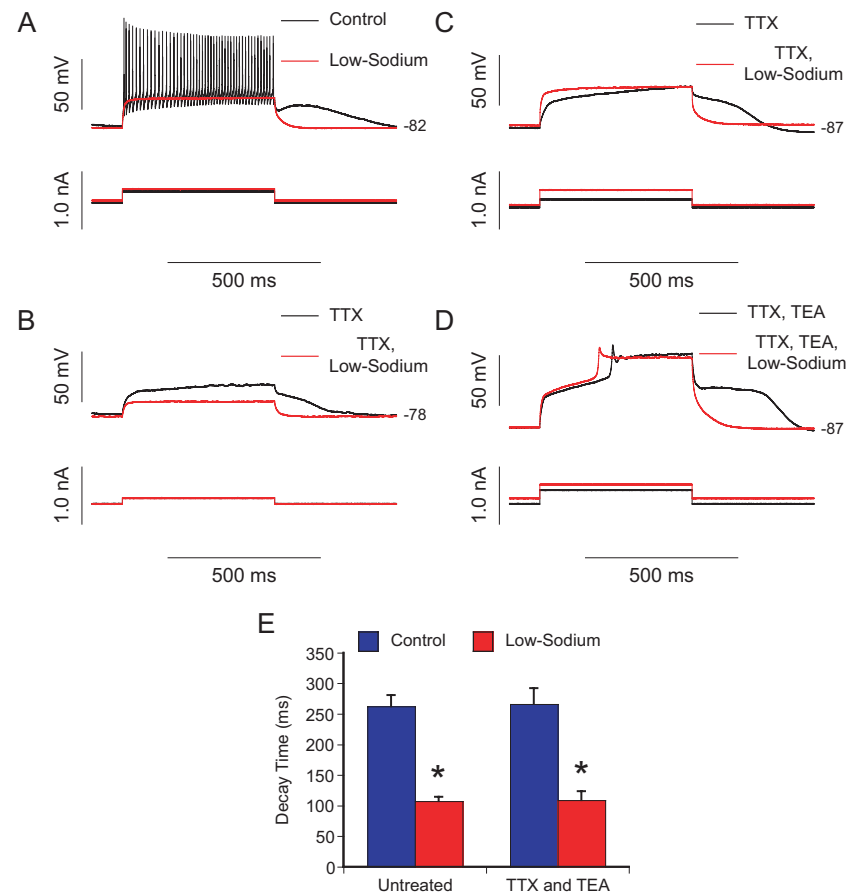

Figure 6. The conductance underlying the plateau potential uses sodium as a charge carrier. $\boldsymbol{A}$, A plateau potential observed after a depolarizing current pulse under control conditions (black trace) was completely abolished in low-sodium buffer (red trace). $\boldsymbol{B}$, Similarly, if voltagegated sodium channels were first blocked with TTX $(2 \mu \mathrm{m})$, the plateau persisted (black trace), but was abolished after superfusion of low-sodium buffer with TTX (red trace). $\boldsymbol{C}$, In another neuron, the plateau potential was also abolished in low-sodium buffer when the neuron was strongly depolarized to the membrane potential it reached when depolarized in TTX alone and the plateau was present. $D$, The plateau unmasked by TEA $(30 \mathrm{~mm})$ in the presence of TTX ( $2 \mu \mathrm{m}$; black trace) was also abolished in low-sodium buffer (red trace). These results are summarized in $\boldsymbol{E}$. Thus, the conductance underlying the plateau potential is activated by calcium, but uses sodium as a charge carrier. ${ }^{*} p<0.0001$.

was also observed when action potentials were first blocked with TTX. The plateau elicited by depolarizing current pulses under these treatments was similarly completely abolished in lowsodium buffer, again regardless of whether or not sodium spiking was first blocked with TTX (Bay K 8644: $300.6 \pm 27.2$ to $122.3 \pm$ $15.8 \mathrm{~ms}, t=-6.49, p<0.001, n=9$; NMDA: $223.7 \pm 20.8$ to $99.1 \pm 5.3 \mathrm{~ms}, t=-5.42, p<0.001, n=10$ ) (Fig. 7). When these neurons were strongly depolarized in low-sodium buffer, allowing the membrane potential achieved during the depolarizing current pulse to reach that achieved with TTX and either Bay K 8644 or NMDA, the plateau continued to be abolished (data not shown).

\section{A calcium-activated nonselective cation conductance} underlies the plateau potential in nigral GABAergic neurons The aforementioned results revealed that the plateau potential is dependent on calcium, but the conductance underlying the plateau uses sodium as a charge carrier. These are characteristics of a calcium-activated nonselective cation conductance $\left(I_{\mathrm{CAN}}\right)$, which can be blocked by flufenamic acid (Shaw et al., 1995; Partridge and Valenzuela, 2000; Hill et al., 2004).

The $I_{\text {CAN }}$ blocker flufenamic acid $(10-200 \mu \mathrm{M})$ was applied to neurons exhibiting a plateau under various conditions (Fig. 8). Flufenamic acid completely abolished the plateau observed after depolarization under control conditions or in the presence of $\operatorname{TTX}(246.3 \pm 21.3$ to $67.4 \pm 13.4 \mathrm{~ms} ; t=-9.26 ; p<0.0001 ; n=$ 9). In addition, when the plateau was abolished by flufenamic 


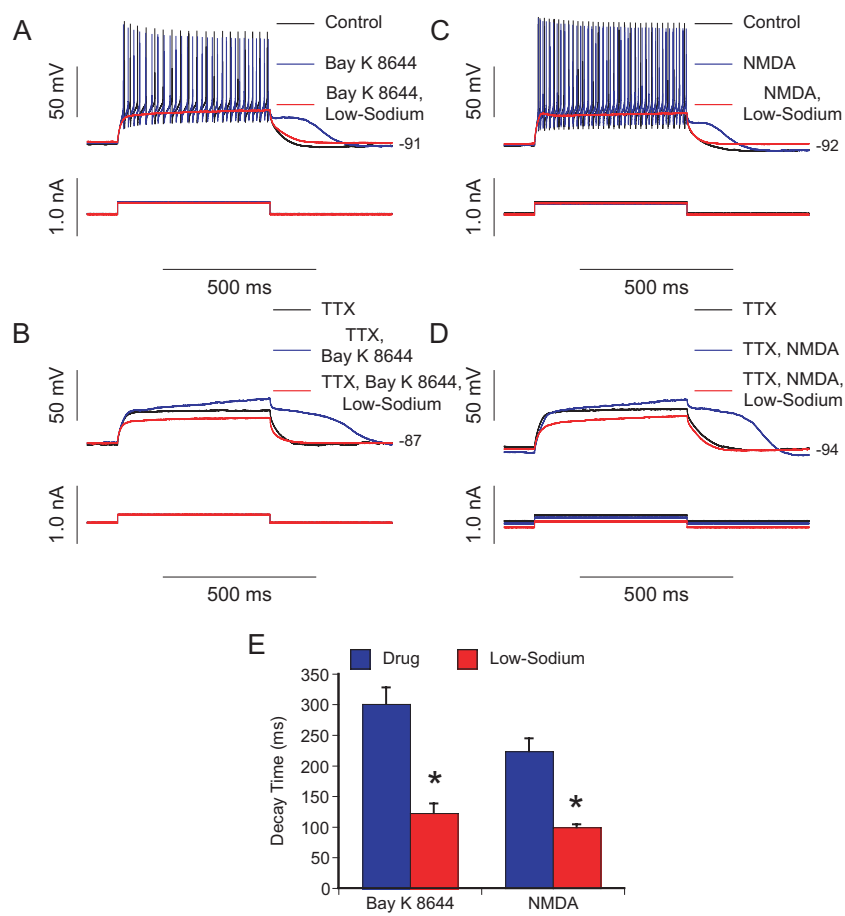

Figure 7. The plateau potential evoked after increasing calcium conductances also uses sodium as a charge carrier. $\boldsymbol{A}$, The plateau potential evoked after superfusion of Bay K 8644 (5 $\mu \mathrm{m}$; black trace, control; blue trace, Bay K 8644) was completely abolished after superfusion of low-sodium buffer (red trace). $\boldsymbol{B}$, These results were identical when action potentials were first blocked by TTX [ $2 \mu \mathrm{m}$; black trace, TTX alone; blue trace, TTX and Bay K 8644 ( $5 \mu \mathrm{m}$ ); red trace, TTX and Bay K 8644 in low-sodium buffer]. C, Similarly, the plateau potential evoked in NMDA ( $30 \mu \mathrm{m}$; black trace, control; blue trace, NMDA) was also completely abolished in low-sodium buffer (red trace). $\boldsymbol{D}$, Identical results were obtained when action potentials were first blocked by TTX [ $2 \mu \mathrm{m}$; black trace, TTX alone; blue trace, TTX and NMDA (30 $\mu \mathrm{m})$; red trace, TTX and NMDA in low-sodium buffer]. These results are summarized in $\boldsymbol{E} .{ }^{*} p<0.001$.

acid in the presence of TTX, depolarizing the neuron to the level achieved in TTX alone did not reveal the plateau (Fig. $8 B$, blue trace). The prolonged increase in firing rate observed when neurons exhibiting the plateau were depolarized from rest (Fig. $8 C$ ) was blocked by flufenamic acid $(10 \mu \mathrm{M})$ (Fig. $8 D$ ). The plateau unmasked by TEA in the presence of TTX was also abolished $(284.1 \pm 26.2$ to $112.9 \pm 9.8 \mathrm{~ms} ; t=-7.12 ; p<0.0001 ; n=11)$.

The plateau observed after increasing calcium conductances with either Bay K 8644 or NMDA was similarly abolished by flufenamic acid (Bay K 8644: $256.6 \pm 17.9$ to $84.6 \pm 12.0 \mathrm{~ms}, t=$ $-9.33, p<0.0001, n=8$; NMDA: $235.1 \pm 42.9$ to $62.5 \pm 11.8$ $\mathrm{ms}, t=-5.09, p<0.01, n=7)$. These results suggest that $I_{\mathrm{CAN}}$ underlies the plateau potential observed in nigral GABAergic neurons after depolarization under control conditions as well as that observed after depolarization while increasing calcium conductances or blocking potassium conductances.

\section{Increasing calcium conductances may cause burst firing in nigral GABAergic neurons}

Application of Bay K 8644 (5 $\mu \mathrm{M})$ caused some neurons initially exhibiting regular spiking spontaneous activity to exhibit bursting both during spontaneous activity with a small hyperpolarizing bias current (Fig. $9 B$ ) and in response to depolarization from a hyperpolarized holding potential (Fig. $9 C, D$ ). In some cases in which burst firing was observed during depolarization, a plateau potential was also present (Fig. 9C). In others, burst firing outlasted the depolarizing current pulse and appeared to be supported by the plateau (Fig. 9D). The burst firing exhibited by
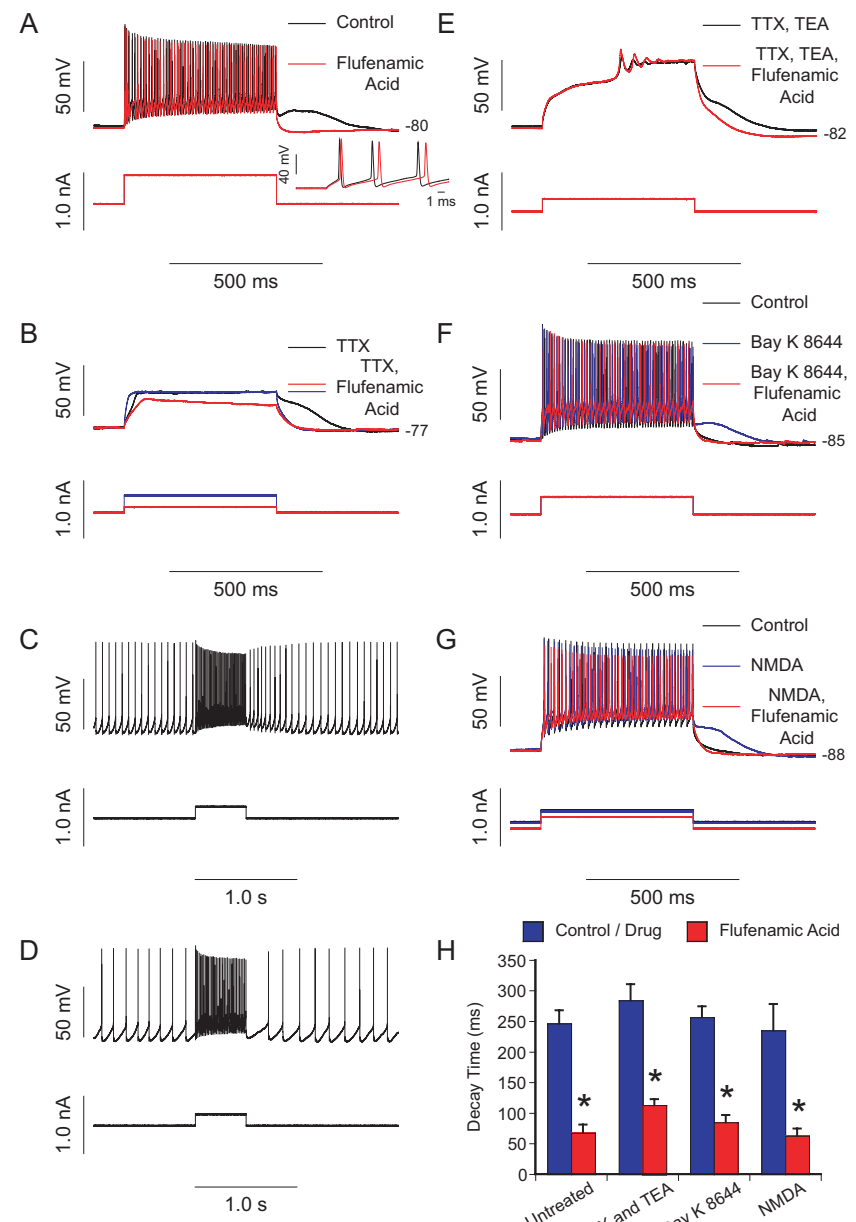

G

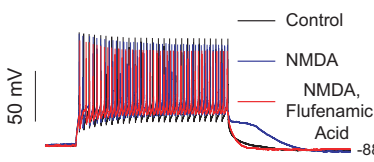

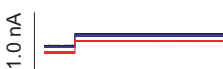

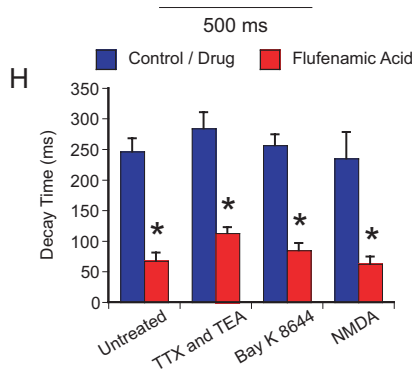

Figure 8. The specific calcium-activated nonselective cation conductance $\left(I_{\text {CAN }}\right)$ blocker flufenamic acid abolishes the plateau potential. $A$, A plateau potential elicited under control conditions (black trace) was completely abolished by flufenamic acid ( $200 \mu \mathrm{m}$; red trace). Inset, The first three action potentials from the traces above it. Action potentials appear largely similar before and after flufenamic acid. $\boldsymbol{B}$, The plateau potential observed in the presence of TTX (black trace) was similarly abolished by flufenamic acid ( $200 \mu \mathrm{m}$; red trace), even when the neuron was depolarized to the potential achieved with TTX alone. $\boldsymbol{C}$, The prolonged increase in firing rate observed after depolarization from rest $(\boldsymbol{C})$ was also abolished by a low concentration of flufenamic acid (10 $\mu \mathrm{m} ; \boldsymbol{D}) . \boldsymbol{E}$, A plateau unmasked by TEA $(30 \mathrm{~mm})$ in the presence of TTX ( $2 \mu \mathrm{M}$; black trace) was also abolished by flufenamic acid (200 $\mu$ m; red trace), as was that evoked in the presence of Bay K 8644 [ $\boldsymbol{F} ; 5 \mu \mathrm{m}$; black trace, control; blue trace, Bay K 8644; red trace, flufenamic acid (200 $\mu \mathrm{m})$ and Bay K 8644] and NMDA [G; $30 \mu \mathrm{m}$; black trace, control; blue trace, NMDA; red trace, flufenamic acid $(200 \mu \mathrm{m})$ and NMDA]. These results are summarized in $\boldsymbol{H}$. Thus, a calcium-activated nonselective cation conductance underlies the plateau potential in nigral GABAergic neurons. ${ }^{*} p<0.01$.

these neurons in the presence of Bay K 8644 was similar to the rhythmic activity exhibited by nigral output neurons in response to dopaminergic denervation, as in Parkinson's disease (Bergman et al., 1994, 1998; Nini et al., 1995; Murer et al., 1997; Hurtado et al., 1999; Raz et al., 2000; Degos et al., 2005; Heimer et al., 2006). These results suggest that activation of L-type calcium conductances leads to activation of $I_{\mathrm{CAN}}$, which likely contributes to burst firing in these neurons.

\section{Discussion}

Nigral GABAergic neurons exhibit a plateau potential when depolarized from a hyperpolarized membrane potential that is caused by a nonselective cation conductance activated by calcium entry through L-type calcium conductances. In most neurons, 
A

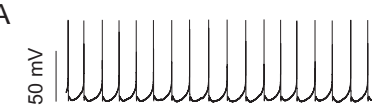

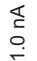

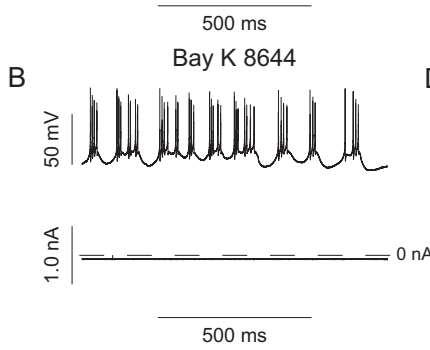

C
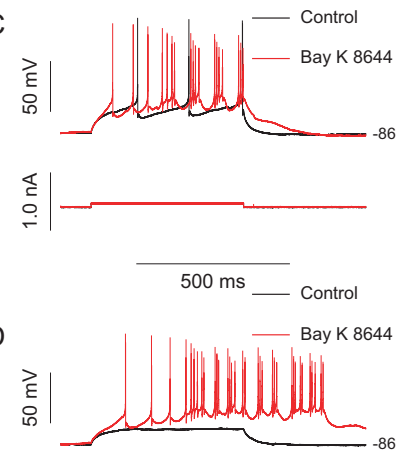

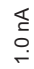

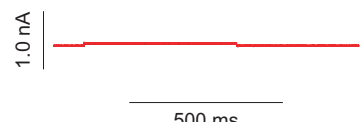

Figure 9. Activation of L-type calcium conductances causes burst firing in nigral GABAergic neurons. $A$, A nigral GABAergic neuron exhibits regular spiking spontaneous activity at rest. $\boldsymbol{B}$, After application of the L-type calcium channel agonist Bay K $8644(5 \mu \mathrm{M})$, the neuron shifts to a bursty pattern. A small hyperpolarizing bias current was applied to prevent excessive depolarization. C, Burst firing and the emergence of a plateau potential is evident in response to depolarization from a hyperpolarized holding potential in the presence of Bay K 8644 (black trace, control; red trace, Bay K 8644). D, In some traces, bursting was observed to outlast the depolarizing current pulse (black trace, control; red trace, Bay $\mathrm{K} 8644$ ). These results suggest that activation of L-type calcium conductances leads to activation of $I_{\text {CAN }}$, which causes burst firing in nigral GABAergic neurons.

the plateau is masked by TEA-sensitive potassium conductances, leading to its appearance after a depolarizing current pulse in only approximately one-third of neurons in control conditions. Blocking these potassium conductances or increasing calcium conductances through L-type calcium channels or NMDA receptors leads to the appearance of the plateau after depolarizing current pulses in the remaining neurons. Nigral GABAergic neurons are not unique in their ability to exhibit plateau potentials, and much can be inferred about the function of the plateau potential in these neurons by examining the effects and molecular substrates of plateau potentials in other neurons of the CNS.

Although the exact type of channel underlying the plateau potential is unknown, given its activation by calcium and permeability to sodium, it is likely to be a melastatin-related transient receptor potential cation channel (TRPM) and most likely a TRPM2 channel. TRPM2 channels are found primarily in the brain, are regulated by calcium, and are nonselective to monovalent cations as well as to calcium (Fleig and Penner, 2004). In addition, human recombinant TRPM2 channels have been shown to be blocked by flufenamic acid (Hill et al., 2004).

\section{Plateau potentials in other neurons}

In the basal ganglia, the presence of a plateau potential and calcium-activated nonselective cation conductance is not unique to GABAergic neurons in the substantia nigra. Nigral dopaminergic neurons exhibit a plateau potential in response to depolarizing current pulses after potassium conductances are blocked (Mercuri et al., 1994; Ping and Shepard, 1999). Plateau potentials are also observed in nigral dopaminergic neurons after depolarization by glutamate in the presence of nicotinic acetylcholine receptor activation and can be abolished with flufenamic acid (Yamashita and Isa, 2003a). The functional significance of $I_{\text {CAN }}$ in the dopaminergic neurons may be to augment excitatory inputs and contribute to burst firing (Yamashita and Isa 2003a, 2004). In these neurons, activation of $I_{\mathrm{CAN}}$ appears to involve the

calcium/calmodulin-CaMKIII (calcium/calmodulin-dependent protein kinase II) pathway (Yamashita and Isa, 2003b).

Neostriatal medium spiny neurons respond to metabolic stress with depolarization, which is blocked by flufenamic acid (Bao et al., 2005), and calcium-activated nonselective cation conductances may contribute to a plateau potential observed in those neurons (Hernandez-Lopez et al., 1997; Vergara et al., 2003).

Closely related to the substantia nigra pars reticulata, GABAergic output neurons of the entopeduncular nucleus also exhibit plateau depolarizations in response to depolarizing current pulses as well as stimulation of the subthalamic nucleus (Nakanishi et al., 1990, 1991).

The best studied example of $I_{\mathrm{CAN}}$ in the basal ganglia is in the subthalamic nucleus, in which a subset of neurons exhibits a plateau potential in response to depolarization from a hyperpolarized holding potential either by depolarizing current pulses or in response to EPSPs (Nakanishi et al., 1987a; Overton and Greenfield, 1995; Beurrier et al., 1999; Otsuka et al., 2001, 2004; Garcia et al., 2003). Like the conductance underlying the plateau potential in nigral GABAergic neurons described here, an inward current can be induced by NMDA or activation of L-type calcium conductances in subthalamic nucleus neurons and is blocked by flufenamic acid (Baufreton et al., 2003; Zhu et al., 2005).

The function of $I_{\text {CAN }}$ in nigral GABAergic neurons is likely similar to that in subthalamic nucleus neurons. $I_{\mathrm{CAN}}$ and its associated plateau potential is important in controlling the firing pattern of subthalamic nucleus neurons which exhibit tonic, single spike firing, burst firing, as well as a quiescent plateau depolarization under some conditions (Beurrier et al., 1999; Zhu et al., 2004; Kass and Mintz, 2006). Burst firing can be observed in these neurons after release of hyperpolarizing current pulses or application of NMDA, both of which also elicit the plateau potential in subthalamic neurons (Beurrier et al., 1999; Zhu et al., 2004, 2005). Cells that lack the plateau have been reported to similarly lack the capacity to exhibit burst firing (Beurrier et al., 1999). Flufenamic acid abolishes NMDA-induced bursting, suggesting that the presence of the plateau potential leads to the emergence of more bursty firing patterns in these neurons (Zhu et al., 2004). Thus, the plateau potential can control the discharge pattern of neurons by increasing their excitability and allowing them to fire in bursts.

\section{Functional significance of the plateau potential in nigral GABAergic neurons}

Nigral GABAergic neurons receive a glutamatergic input from the subthalamic nucleus (Hammond et al., 1978; Van Der Kooy and Hattori, 1980; Robledo and Feger, 1990; Bevan et al., 1994; Iribe et al., 1999; Ibanez-Sandoval et al., 2006) and can respond to stimulation of the subthalamic nucleus with plateau potentials (Nakanishi et al., 1987b). We have shown here that one mechanism that can elicit the plateau potential is NMDA receptor activation. It is possible that input from the subthalamic nucleus could contribute to the emergence of plateau potentials in nigral GABAergic neurons, which could lead to increased excitability and burst firing in the nigral output neurons. A recent study has demonstrated that nigral GABAergic neurons can exhibit a burst of action potentials in response to electrical stimulation of the subthalamic nucleus in vitro (Shen and Johnson, 2006). As shown here, activation of L-type calcium conductances caused bursting in some neurons. Activation of either NMDA receptors or L-type calcium channels leads to the activation of $I_{\mathrm{CAN}}$, which likely underlies the burst firing. Because the plateau potential can be enhanced by attenuating potassium conductances, it is likely that 
by increasing calcium conductances while at the same time attenuating potassium conductances, the effect of $I_{\mathrm{CAN}}$ on the firing pattern could be heightened and become more evident.

The functional significance of burst firing in both the subthalamic nucleus and substantia nigra pars reticulata may be best recognized in terms of pathological conditions such as Parkinson's disease. Although some of the motor symptoms of Parkinson's disease are likely caused by increased output from the substantia nigra pars reticulata and internal globus pallidus (Albin et al., 1989; DeLong, 1990), the firing pattern of basal ganglia output neurons has been increasingly recognized as an important variable in basal ganglia and motor function.

The firing of nigral and internal globus pallidus GABAergic neurons is largely tonic and regular under most conditions but acquires a bursty, correlated firing pattern in Parkinson's disease or after dopaminergic denervation (MacLeod et al., 1990; Hutchison et al., 1994; Nini et al., 1995; Murer et al., 1997; Bergman et al., 1998; Hurtado et al., 1999; Wichmann et al., 1999; Raz et al., 2000; Ruskin et al., 2002; Boraud et al., 2005). Additionally, glutamatergic inputs to nigral output neurons from the subthalamic nucleus also exhibit increased output and burst firing under conditions of dopaminergic denervation (Albin et al., 1989; DeLong, 1990; Bergman et al., 1994; Rodriguez-Oroz et al., 2001; Levy et al., 2002; Sharott et al., 2005). This would presumably lead to increased, rhythmic activation of postsynaptic NMDA receptors on nigral output neurons. As shown here, activation of NMDA receptors increases activation of the $I_{\mathrm{CAN}}$, which likely contributes to the rhythmic firing of nigral output neurons in Parkinson's disease.

Whether the loss of dopamine in Parkinson's disease would result in upregulation of $I_{\mathrm{CAN}}$, or calcium conductances activating $I_{\mathrm{CAN}}$, is unknown. Subthalamic nucleus neurons recorded in vitro from dopaminergic denervated mice show increases in irregular firing, which are resistant to blockade of ionotropic glutamatergic and GABAergic receptors, suggesting that intrinsic mechanisms such as the plateau potential may be upregulated in those neurons and contribute to the shift away from more regular firing patterns (Wilson et al., 2006). However, it has also been reported that dopamine receptor activation potentiates burst firing in subthalamic nucleus neurons in vitro (Baufreton et al., 2003). It is nevertheless highly likely that the plateau potential contributes significantly to the burst firing observed in nigral output neurons in Parkinson's disease regardless of whether it is upregulated by the loss of dopamine or more strongly activated through increased activation of NMDA or other voltage-gated calcium channels.

Present treatments for Parkinson's disease such as highfrequency stimulation of the subthalamic nucleus and dopaminergic replacement have been shown to exert their effects, at least in part, by regularizing abnormal oscillations in the basal ganglia (Bergman et al., 1990; Tseng et al., 2001; Levy et al., 2002; Brown et al., 2004; Degos et al., 2005; Meissner et al., 2005; Heimer et al., 2006; Kuhn et al., 2006). It is conceivable that by blocking $I_{\text {CAN }}$, the excitability of nigral output neurons could be decreased and their firing returned to more regular patterns thereby helping to ameliorate the symptoms of Parkinson's disease and other dyskinesias.

\section{References}

Albin RL, Young AB, Penney JB (1989) The functional anatomy of basal ganglia disorders. Trends Neurosci 12:366-375.

Atherton JF, Bevan MD (2005) Ionic mechanisms underlying autonomous action potential generation in the somata and dendrites of GABAergic substantia nigra pars reticulata neurons in vitro. J Neurosci 25:8272-8281.

Bao L, Avshalumov MV, Rice ME (2005) Partial mitochondrial inhibition causes striatal dopamine release suppression and medium spiny neuron depolarization via $\mathrm{H}_{2} \mathrm{O}_{2}$ elevation, not ATP depletion. J Neurosci 25:10029-10040.

Barry PH (1994) JPCalc, a software package for calculating liquid junction potential corrections in patch-clamp, intracellular, epithelial and bilayer measurements and for correcting junction potential measurements. J Neurosci Methods 51:107-116.

Baufreton J, Garret M, Rivera A, de la Calle A, Gonon F, Dufy B, Bioulac B, Taupignon A (2003) $\mathrm{D}_{5}$ (not $\mathrm{D}_{1}$ ) dopamine receptors potentiate burstfiring in neurons of the subthalamic nucleus by modulating an L-type calcium conductance. J Neurosci 23:816-825.

Bergman H, Wichmann T, DeLong MR (1990) Reversal of experimental parkinsonism by lesions of the subthalamic nucleus. Science 249:1436-1438.

Bergman H, Wichmann T, Karmon B, DeLong MR (1994) The primate subthalamic nucleus. II. Neuronal activity in the MPTP model of parkinsonism. J Neurophysiol 72:507-520.

Bergman H, Feingold A, Nini A, Raz A, Slovin H, Abeles M, Vaadia E (1998) Physiological aspects of information processing in the basal ganglia of normal and parkinsonian primates. Trends Neurosci 21:32-38.

Beurrier C, Congar P, Bioulac B, Hammond C (1999) Subthalamic nucleus neurons switch from single-spike activity to burst-firing mode. J Neurosci 19:599-609.

Bevan MD, Bolam JP, Crossman AR (1994) Convergent synaptic input from the neostriatum and the subthalamus onto identified nigrothalamic neurons in the rat. Eur J Neurosci 6:320-334.

Boraud T, Brown P, Goldberg JA, Graybiel AM, Magill PJ (2005) Oscillations in the basal ganglia: the good, the bad, and the unexpected. In: The basal ganglia VIII (Bolam JP, Ingham CA, Magill PJ, eds), pp 3-24. New York: Springer Science and Business Media.

Brown P, Mazzone P, Oliviero A, Altibrandi MG, Pilato F, Tonali PA, Di Lazzaro V (2004) Effects of stimulation of the subthalamic area on oscillatory pallidal activity in Parkinson's disease. Exp Neurol 188:480 -490.

Celada P, Paladini CA, Tepper JM (1999) GABAergic control of rat substantia nigra dopaminergic neurons: role of globus pallidus and substantia nigra pars reticulata. Neuroscience 89:813-825.

Chevalier G, Deniau JM (1990) Disinhibition as a basic process in the expression of striatal functions. Trends Neurosci 13:277-280.

Degos B, Deniau JM, Thierry AM, Glowinski J, Pezard L, Maurice N (2005) Neuroleptic-induced catalepsy: electrophysiological mechanisms of functional recovery induced by high-frequency stimulation of the subthalamic nucleus. J Neurosci 25:7687-7696.

DeLong MR (1990) Primate models of movement disorders of basal ganglia origin. Trends Neurosci 13:281-285.

Deniau JM, Hammond C, Riszk A, Feger J (1978) Electrophysiological properties of identified output neurons of the rat substantia nigra (pars compacta and pars reticulata): evidences for the existence of branched neurons. Exp Brain Res 32:409-422.

Deniau JM, Kitai ST, Donoghue JP, Grofova I (1982) Neuronal interactions in the substantia nigra pars reticulata through axon collaterals of the projection neurons. An electrophysiological and morphological study. Exp Brain Res 47:105-113.

Fleig A, Penner R (2004) The TRPM ion channel subfamily: molecular, biophysical and functional features. Trends Pharmacol Sci 25:633-639.

Garcia L, Audin J, D’Alessandro G, Bioulac B, Hammond C (2003) Dual effect of high-frequency stimulation on subthalamic neuron activity. J Neurosci 23:8743-8751.

Gonzalez-Hernandez T, Rodriguez M (2000) Compartmental organization and chemical profile of dopaminergic and GABAergic neurons in the substantia nigra of the rat. J Comp Neurol 421:107-135.

Grace AA, Onn SP (1989) Morphology and electrophysiological properties of immunocytochemically identified rat dopamine neurons recorded in vitro. J Neurosci 9:3463-3481.

Gulácsi A, Lee CR, Sik A, Viitanen T, Kaila K, Tepper JM, Freund TF (2003) Cell type-specific differences in chloride-regulatory mechanisms and $\mathrm{GABA}_{\mathrm{A}}$ receptor-mediated inhibition in rat substantia nigra. J Neurosci 23:8237-8246.

Guyenet PG, Aghajanian GK (1978) Antidromic identification of dopami- 
nergic and other output neurons of the rat substantia nigra. Brain Res 150:69-84.

Hajos M, Greenfield SA (1994) Synaptic connections between pars compacta and pars reticulata neurones: electrophysiological evidence for functional modules within the substantia nigra. Brain Res 660:216-224.

Hammond C, Deniau JM, Rizk A, Feger J (1978) Electrophysiological demonstration of an excitatory subthalamonigral pathway in the rat. Brain Res 151:235-244.

Harris NC, Constanti A (1995) Mechanism of block by ZD 7288 of the hyperpolarization-activated inward rectifying current in guinea pig substantia nigra neurons in vitro. J Neurophysiol 74:2366-2378.

Heimer G, Rivlin-Etzion M, Bar-Gad I, Goldberg JA, Haber SN, Bergman H (2006) Dopamine replacement therapy does not restore the full spectrum of normal pallidal activity in the 1-methyl-4-phenyl-1,2,3,6-tetrahydropyridine primate model of parkinsonism. J Neurosci 26:8101-8114.

Hernandez-Lopez S, Bargas J, Surmeier DJ, Reyes A, Galarraga E (1997) $D_{1}$ receptor activation enhances evoked discharge in neostriatal medium spiny neurons by modulating an L-type $\mathrm{Ca}^{2+}$ conductance. J Neurosci 17:3334-3342.

Hill K, Benham CD, McNulty S, Randall AD (2004) Flufenamic acid is a $\mathrm{pH}$-dependent antagonist of TRPM2 channels. Neuropharmacology 47:450-460.

Hurtado JM, Gray CM, Tamas LB, Sigvardt KA (1999) Dynamics of tremorrelated oscillations in the human globus pallidus: a single case study. Proc Natl Acad Sci USA 96:1674-1679.

Hutchison WD, Lozano AM, Davis KD, Saint-Cyr JA, Lang AE, Dostrovsky JO (1994) Differential neuronal activity in segments of globus pallidus in Parkinson's disease patients. NeuroReport 5:1533-1537.

Ibanez-Sandoval O, Hernandez A, Floran B, Galarraga E, Tapia D, Valdiosera R, Erlij D, Aceves J, Bargas J (2006) Control of the subthalamic innervation of substantia nigra pars reticulata by $\mathrm{D}_{1}$ and $\mathrm{D}_{2}$ dopamine receptors. J Neurophysiol 95:1800-1811.

Iribe Y, Moore K, Pang KC, Tepper JM (1999) Subthalamic stimulationinduced synaptic responses in substantia nigra pars compacta dopaminergic neurons in vitro. J Neurophysiol 82:925-933.

Kass JI, Mintz IM (2006) Silent plateau potentials, rhythmic bursts, and pacemaker firing: three patterns of activity that coexist in quadristable subthalamic neurons. Proc Natl Acad Sci USA 103:183-188.

Kuhn AA, Kupsch A, Schneider GH, Brown P (2006) Reduction in subthalamic $8-35 \mathrm{~Hz}$ oscillatory activity correlates with clinical improvement in Parkinson's disease. Eur J Neurosci 23:1956-1960.

Lacey MG, Mercuri NB, North RA (1989) Two cell types in rat substantia nigra zona compacta distinguished by membrane properties and the actions of dopamine and opioids. J Neurosci 9:1233-1241.

Lee CR, Tepper JM (2005) Plateau potentials in GABAergic neurons of the rat substantia nigra. Soc Neurosci Abstr 31:987.9.

Lee CR, Tepper JM (2007) Morphological and physiological properties of parvalbumin and calretinin containing GABAergic neurons in the substantia nigra. J Comp Neurol 500:958-972.

Lestienne F, Caillier P (1986) Role of the monkey substantia nigra pars reticulata in orienting behaviour and visually triggered arm movements. Neurosci Lett 64:109-115.

Levy R, Ashby P, Hutchison WD, Lang AE, Lozano AM, Dostrovsky JO (2002) Dependence of subthalamic nucleus oscillations on movement and dopamine in Parkinson's disease. Brain 125:1196-1209.

MacLeod NK, Ryman A, Arbuthnott GW (1990) Electrophysiological properties of nigrothalamic neurons after 6-hydroxydopamine lesions in the rat. Neuroscience 38:447-456.

Mailly P, Charpier S, Mahon S, Menetrey A, Thierry AM, Glowinski J, Deniau JM (2001) Dendritic arborizations of the rat substantia nigra pars reticulata neurons: spatial organization and relation to the lamellar compartmentation of striato-nigral projections. J Neurosci 21:6874-6888.

Mailly P, Charpier S, Menetrey A, Deniau JM (2003) Three-dimensional organization of the recurrent axon collateral network of the substantia nigra pars reticulata neurons in the rat. J Neurosci 23:5247-5257.

Matsuda Y, Fujimura K, Yoshida S (1987) Two types of neurons in the substantia nigra pars compacta studied in a slice preparation. Neurosci Res 5:172-179.

Meissner W, Leblois A, Hansel D, Bioulac B, Gross CE, Benazzouz A, Boraud $\mathrm{T}$ (2005) Subthalamic high frequency stimulation resets subthalamic firing and reduces abnormal oscillations. Brain 128:2372-2382.
Mercuri NB, Bonci A, Calabresi P, Stratta F, Stefani A, Bernardi G (1994) Effects of dihydropyridine calcium antagonists on rat midbrain dopaminergic neurones. Br J Pharmacol 113:831-838.

Murer MG, Riquelme LA, Tseng KY, Pazo JH (1997) Substantia nigra pars reticulata single unit activity in normal and 60HDA-lesioned rats: effects of intrastriatal apomorphine and subthalamic lesions. Synapse 27:278-293.

Nakanishi H, Kita H, Kitai ST (1987a) Electrical membrane properties of rat subthalamic neurons in an in vitro slice preparation. Brain Res 437:35-44.

Nakanishi H, Kita H, Kitai ST (1987b) Intracellular study of rat substantia nigra pars reticulata neurons in an in vitro slice preparation: electrical membrane properties and response characteristics to subthalamic stimulation. Brain Res 437:45-55.

Nakanishi H, Kita H, Kitai ST (1990) Intracellular study of rat entopeduncular nucleus neurons in an in vitro slice preparation: electrical membrane properties. Brain Res 527:81-88.

Nakanishi H, Kita H, Kitai ST (1991) Intracellular study of rat entopeduncular nucleus neurons in an in vitro slice preparation: response to subthalamic stimulation. Brain Res 549:285-291.

Neuhoff H, Neu A, Liss B, Roeper J (2002) $I_{\mathrm{h}}$ channels contribute to the different functional properties of identified dopaminergic subpopulations in the midbrain. J Neurosci 22:1290-1302.

Nini A, Feingold A, Slovin H, Bergman H (1995) Neurons in the globus pallidus do not show correlated activity in the normal monkey, but phaselocked oscillations appear in the MPTP model of parkinsonism. J Neurophysiol 74:1800-1805.

Nitsch C, Riesenberg R (1988) Immunocytochemical demonstration of GABAergic synaptic connections in rat substantia nigra after different lesions of the striatonigral projection. Brain Res 461:127-142.

Otsuka T, Murakami F, Song WJ (2001) Excitatory postsynaptic potentials trigger a plateau potential in rat subthalamic neurons at hyperpolarized states. J Neurophysiol 86:1816-1825.

Otsuka T, Abe T, Tsukagawa T, Song WJ (2004) Conductance-based model of the voltage-dependent generation of a plateau potential in subthalamic neurons. J Neurophysiol 92:255-264.

Overton PG, Greenfield SA (1995) Determinants of neuronal firing pattern in the guinea-pig subthalamic nucleus: an in vivo and in vitro comparison. J Neural Transm Park Dis Dement Sect 10:41-54.

Partridge LD, Valenzuela CF (2000) Block of hippocampal CAN channels by flufenamate. Brain Res 867:143-148.

Ping HX, Shepard PD (1999) Blockade of SK-type $\mathrm{Ca}^{2+}$-activated K+ channels uncovers a $\mathrm{Ca}^{2+}$-dependent slow afterdepolarization in nigral dopamine neurons. J Neurophysiol 81:977-984.

Raz A, Vaadia E, Bergman H (2000) Firing patterns and correlations of spontaneous discharge of pallidal neurons in the normal and the tremulous 1-methyl-4-phenyl-1,2,3,6-tetrahydropyridine vervet model of parkinsonism. J Neurosci 20:8559-8571.

Richards CD, Shiroyama T, Kitai ST (1997) Electrophysiological and immunocytochemical characterization of GABA and dopamine neurons in the substantia nigra of the rat. Neuroscience 80:545-557.

Rick CE, Lacey MG (1994) Rat substantia nigra pars reticulata neurones are tonically inhibited via $\mathrm{GABA}_{\mathrm{A}}$, but not $\mathrm{GABA}_{\mathrm{B}}$, receptors in vitro. Brain Res 659:133-137.

Robledo P, Feger J (1990) Excitatory influence of rat subthalamic nucleus to substantia nigra pars reticulata and the pallidal complex: electrophysiological data. Brain Res 518:47-54.

Rodriguez-Oroz MC, Rodriguez M, Guridi J, Mewes K, Chockkman V, Vitek J, DeLong MR, Obeso JA (2001) The subthalamic nucleus in Parkinson's disease: somatotopic organization and physiological characteristics. Brain 124:1777-1790.

Ruskin DN, Bergstrom DA, Walters JR (2002) Nigrostriatal lesion and dopamine agonists affect firing patterns of rodent entopeduncular nucleus neurons. J Neurophysiol 88:487-496.

Schultz W (1986) Activity of pars reticulata neurons of monkey substantia nigra in relation to motor, sensory, and complex events. J Neurophysiol 55:660-677.

Sharott A, Magill PJ, Harnack D, Kupsch A, Meissner W, Brown P (2005) Dopamine depletion increases the power and coherence of betaoscillations in the cerebral cortex and subthalamic nucleus of the awake rat. Eur J Neurosci 21:1413-1422.

Shaw T, Lee RJ, Partridge LD (1995) Action of diphenylamine carboxylate 
derivatives, a family of non-steroidal anti-inflammatory drugs, on $\mathrm{Ca}^{2+}{ }_{\mathrm{i}}$ and $\mathrm{Ca}^{2+}$-activated channels in neurons. Neurosci Lett 190:121-124.

Shen KZ, Johnson SW (2006) Subthalamic stimulation evokes complex EPSCs in the rat substantia nigra pars reticulata in vitro. J Physiol (Lond) 573:697-709.

Smith Y, Bolam JP (1991) Convergence of synaptic inputs from the striatum and the globus pallidus onto identified nigrocollicular cells in the rat: a double anterograde labelling study. Neuroscience 44:45-73.

Tseng KY, Kasanetz F, Kargieman L, Pazo JH, Murer MG, Riquelme LA (2001) Subthalamic nucleus lesions reduce low frequency oscillatory firing of substantia nigra pars reticulata neurons in a rat model of Parkinson's disease. Brain Res 904:93-103.

Van Der Kooy D, Hattori T (1980) Single subthalamic nucleus neurons project to both the globus pallidus and substantia nigra in rat. J Comp Neurol 192:751-768.

Vergara R, Rick C, Hernandez-Lopez S, Laville JA, Guzman JN, Galarraga E, Surmeier DJ, Bargas J (2003) Spontaneous voltage oscillations in striatal projection neurons in a rat corticostriatal slice. J Physiol (Lond) 553:169-182.

Wichmann T, Bergman H, DeLong MR (1994) The primate subthalamic nucleus. III. Changes in motor behavior and neuronal activity in the internal pallidum induced by subthalamic inactivation in the MPTP model of parkinsonism. J Neurophysiol 72:521-530.

Wichmann T, Bergman H, Starr PA, Subramanian T, Watts RL, DeLong MR (1999) Comparison of MPTP-induced changes in spontaneous neuronal discharge in the internal pallidal segment and in the substantia nigra pars reticulata in primates. Exp Brain Res 125:397-409.

Wilson CJ, Young SJ, Groves PM (1977) Statistical properties of neuronal spike trains in the substantia nigra: cell types and their interactions. Brain Res 136:243-260.
Wilson CL, Cash D, Galley K, Chapman H, Lacey MG, Stanford IM (2006) Subthalamic nucleus neurones in slices from 1-methyl-4-phenyl-1,2,3,6tetrahydropyridine-lesioned mice show irregular, dopamine-reversible firing pattern changes, but without synchronous activity. Neuroscience 143:565-572.

Windels F, Kiyatkin EA (2004) GABA, not glutamate, controls the activity of substantia nigra reticulata neurons in awake, unrestrained rats. J Neurosci 24:6751-6754.

Windels F, Kiyatkin EA (2006) GABAergic mechanisms in regulating the activity state of substantia nigra pars reticulata neurons. Neuroscience 140:1289-1299.

Yamashita T, Isa T (2003a) Fulfenamic acid sensitive, $\mathrm{Ca}^{2+}$-dependent inward current induced by nicotinic acetylcholine receptors in dopamine neurons. Neurosci Res 46:463-473.

Yamashita T, Isa T (2003b) $\mathrm{Ca}^{2+}$-dependent inward current induced by nicotinic receptor activation depends on $\mathrm{Ca}^{2+} /$ calmodulin-CaMKII pathway in dopamine neurons. Neurosci Res 47:225-232.

Yamashita T, Isa T (2004) Enhancement of excitatory postsynaptic potentials by preceding application of acetylcholine in mesencephalic dopamine neurons. Neurosci Res 49:91-100.

Yung WH, Hausser MA, Jack JJ (1991) Electrophysiology of dopaminergic and non-dopaminergic neurones of the guinea-pig substantia nigra pars compacta in vitro. J Physiol (Lond) 436:643-667.

Zhu ZT, Munhall A, Shen KZ, Johnson SW (2004) Calcium-dependent subthreshold oscillations determine bursting activity induced by $\mathrm{N}$-methylD-aspartate in rat subthalamic neurons in vitro. Eur J Neurosci 19:1296-1304.

Zhu ZT, Munhall A, Shen KZ, Johnson SW (2005) NMDA enhances a depolarization-activated inward current in subthalamic neurons. Neuropharmacology 49:317-327. 